\title{
CONSIGNMENT INVENTORY SIMULATION MODEL FOR SINGLE VENDOR-MULTI BUYERS IN A SUPPLY CHAIN
}

\author{
Chidurala Srinivas \\ Professor, Mechanical Engineering Department \\ Vaageswari College of Engineering \\ Karimnagar, Telangana State, INDIA
}

\begin{abstract}
The focus on the studies of supply chain management has been increasing in recent years among academics as well as practitioners. In this paper, we present an extendable multi agent supply chain simulation model for consignment stock inventory model for a single vendor - multiple buyers. The simulation study dealt the quantitative measures of performance of consignment stock model with respect to number of shipments, delay deliveries, number of shipments shifted due to partial information sharing, average inventory levels of buyer and vendor and joint total economic cost (JTEC) as key performance parameters. Flexsim V3.0 a discrete event simulation software is used for simulating the model.
\end{abstract}

Keywords: Consignment stock, Delay delivery, Information sharing

Cite this Article: Chidurala Srinivas, Consignment Inventory Simulation Model for Single Vendor-Multi Buyers in a Supply Chain, International Journal of Advanced Research in Engineering and Technology, 10 (2), 2019, pp 341-349.

$\mathrm{http} / / /$ iaeme.com/Home/issue/IJARET?Volume $=10 \&$ Issue $=2$

\section{INTRODUCTION}

In today's global market place, firms are no longer competing as independent entities with unique brand names, but rather as an integral part of entire network links. As such, the ultimate success of a firm will depend on its managerial ability to integrate and coordinate the intricate network of business relationships among Supply Chain (SC) members (Drucker, 1998, Douglas $\&$ Cooper, 2000). Since the holding of inventories in a supply chain can cost anywhere between $20 \%$ to $40 \%$ of product value, hence the effective management of inventory is critical in SC operations ( Ballou, 1992) In this environment Supply Chain Management (SCM) has become a means of further adding value to products and to gain a global competitive advantage in the business strategy. Thus, the efficient and effective management of inventory control throughout the supply chain significantly improves and ultimate provides service to the customer (Lee \& Billington, 1992). Houlihan (1985) is credited to be the first person for coining the term SC with insight concepts for viewing the $\mathrm{SC}$ as a strategy is described the holistic approach of integrating the SCM global strategic business decisions. Many definitions of SCM have been mentioned in the literature and in practice, although the underlying philosophy is the same. The 
lack of a universal definition for SCM is because of the multidisciplinary origin and evolution of the concept. Simchi-Levi et al., (2000) defined SCM as a set of approaches utilized to efficiently coordinate and integrate suppliers, manufacturers, warehouses and stores with planning, implementation and control of material, information and money between vendor and buyer along the echelon, so that merchandise is produced and distributed with right quantities, to the right location and at right time in order to minimize system wide cost, while satisfying service level requirements.

In this paper an effective simulation-based inventory control model of Consignment Stock (CS) policy is proposed. In CS model, vendor stocks his finished products at buyer's warehouse without changing the ownership, which leads to suppression of vendor inventory. To fulfill this concept, the vendor should be close to buyer's production line so that the material may be picked up whenever needed. The CS with single vendor multiple buyer models is viewed as a classification of divergent type of supply chain with end 2 multi end case. In CS model vendor adopts push system whereas the change of ownership commences during pull system. This creates a condition of the shared benefit, neither the vendor nor the buyer will benefit until the product is sold to an end user. The key benefit to the buyer is that he doesn't have to tie up his capital. This doesn't mean that there is no inventory carrying costs for buyer, he does still incur costs but, related to storing and managing the inventory. This is very clear, that both parties incur holding costs, however, it depends on different rates and the length of time for which materials are stocked in a general model at echelon locations of SC.

Finally, the buyer sees a lower inventory cost per unit that is, only $h_{b}$ stock instead of the entire $h_{b}$ stock $+h_{b}$ finance further there is no longer any administrative cost per placing an order as in fact there is no longer any order. CS model is conveniently adopted in small size and less cost items. Typically, it is best suitable for automobile spare parts, pharmaceutical, electronic, newspaper, fast moving consumer goods, retail items of super and hyper markets.

\section{LITERATURE REVIEW}

Corbett (2001) is credited to be the first person to give about the fundamentals of consignment stock model. The basic fundamental of consignment stock model is explained in detail in Braglia \& Zavanella (2003), Valentini \& Zavanella (2003), Simone \& Grubbstrom (2004), and Srinivas \& Rao (2006). Valentini \& Zavanella (2003) presented an industrial case and performance analysis of consignment stock policy for a single vendor and single buyer. Braglia \& Zavanella (2003) presented an analytical modeling approach which concerns deterministic single vendor- single buyer allowing the analyst to identify the optimal inventory level and shipment policy for optimizing total costs. He also discussed performance evaluation of CS model, which is an effective alternate to Hills $(1997,1999)$ models. Srinivas \& Rao (2006) developed an analytical single vendor - single buyer inventory model for stochastic demand and controllable lead times.

The authors in this paper have formulated a simulation work which is an extended framework of Srinivas \& Rao (2006) of CS strategy inventory model for a stochastic nature of single vendor - single buyer for single product and further extended to single vendor-multi buyers dealing for single product under stochastic demands.

\section{SIMULATION MODEL}

To compute real world situations, simulation is widely used by many researchers to study the performance of the supply chain, as it aims to build models with many realistic details and enables us to understand the dynamical interactions among various members. By definition simulation is an experimental method, i.e., the analysts experiment with different input values 
and different model structures representing different policies/criteria. Towill et al., (1992) used simulation as a means to evaluate the impact of various inventory policies.

In this paper, Flexsim v 3.0 software is used to build supply chain simulation models, which is a discrete event simulation to handle stochastic behavior throughout the SC. Flexsim is a powerful analysis tool that helps to make intelligent decisions in the design and operation of a system. The optimum values obtained from the enumerate technique analysis of single vendor - single buyer (Srinivas \& Rao, 2006) and Genetic Algorithm (GA) based analytical model of single vendor - multi buyer (Srinivas \& Rao, 2006a) are referred as input to the developed Flexsim simulation models, which evaluate the effects of various decision variables on SC performance.

The various quantitative performance parameters considered in this simulation work are; number of shipments, number of delay deliveries, number of shipments shifted due to partial information sharing, ordering quantities, average inventory levels of buyer and vendor and total cost.

\subsection{Simulation Model setups}

The consignment stock simulation model has been simulated for three different models for single vendor multiple buyers such as:

- Consignment stock without delay delivery (M1).

- Consignment stock with delay delivery (M2).

- Consignment stock with partial information sharing (M3).

In GA based analysis these models are named as M4, M5 and M6.

\subsubsection{Consignment stock without delay delivery}

It is a basic consignment stock model. The inventory cost per unit is driven by two components: a financial cost $\left(\mathrm{h}_{\mathrm{fin}}\right)$ and holding cost $\left(\mathrm{h}_{\mathrm{hold}}\right)$. When the product is with vendor, he incurs both $\mathrm{h}_{\mathrm{v} \text { fin }}$ and $\mathrm{h}_{\mathrm{v} \text { hold, }}$, buyer did not incur any cost. When the product is with buyer, vendor still incurs $\mathrm{h}_{\mathrm{v} \text { fin }}$, where as buyer incurs only $\mathrm{h}_{\mathrm{v}}$ hold. In traditional models, when product is with vendor he incurs $h_{v}$ fin and $h_{v}$ hold buyer did not incur any cost, when it is with buyer incurs $h_{b}$ fin and $h_{b}$ hold, vendor did not incur any cost. In CS model, the buyer sees a lower inventory cost per unit that is, only $h_{b}$ stock instead of the entire $h_{b}$ stock $+h_{b}$ finance further there is no longer any administrative cost for placing an order as in fact there is no longer any order.

The inventory position at a member is defined as the total on hand inventory minus back order quantity. In continuous review period model, the net inventory position is set to try to restore to as,

$$
\left[\sum_{\mathrm{n}=1}^{\mathrm{i}}\left(\mathrm{I}_{\mathrm{n}}+T_{n}\right)-D_{n}\right] \geqslant \text { safetystock }
$$

For buyer i, the replenishment quantity is the difference between its safety stock and the current inventory level. The ordering quantity is replenished in such a way that there will not be any shortages during the replenishment. However, shortages may exist after end of the replenishment period. It is due to the stochastic environment; hence it is necessary to maintain certain safety stock along the echelons.

\subsubsection{Consignment stock with delay delivery}

In this model, the last delivery in the corresponding cycle will be delayed whenever maximum level of buyer's inventory is reached until the moment when it no longer determines further increase in the maximum level already reached. In this model as there is no information sharing between vendor and buyer, the delayed deliveries are retained by vendor. This will increase 
vendor inventory cost and reduce buyer inventory costs. However, the net effect will be reduction in JTEC due to saving in shipment cost and inventory costs $\left(\mathrm{h}_{\mathrm{bi}}>\mathrm{h}_{\mathrm{v}}\right)$.

\subsubsection{Consignment stock with information sharing}

In an integrated partial information sharing the unwanted scheduled delivery of a particular buyer will be shifted to another buyer. Here we assume that in the shifting process, the quantity shipped is same, as the quantity required to that buyer at that time, for this the vendor will make adjustments from his stock. The information sharing through Electronic Data Interchange (EDI), Radio Frequency Identification (RFID) of web-based technology reduces \& shortens the time lag in communication, order processing and shipment which intern reduces the inventory and other related costs (Banerjee \& Banerjee, 1994). These techniques make feasible for multiple buyers and the supplier to be linked together on a real time basis and it is possible for the supplier to monitor the consumption pattern of the buyers, if so desired. It is noticed that the centralized partial information sharing would involve some investment in information technology enabled EDI/RFID. This investment is made keeping long term relationship among business parameters and flexibility of business. Sharing information such as demand, inventory status and order fulfillment status can help companies to reduce inventory cost, shorten lead time and improve decision making along the SC. Strader et al., (1998) used multi agent simulation as a tool to study the impact of information sharing on order fulfillment in divergent assembly supply chain, Closs et al., (1998), found that information sharing enables inventory costs to be reduced dramatically comparison to the traditional strategies, while maintaining acceptable order fulfillment cycle times. This model is given in Fig.1.

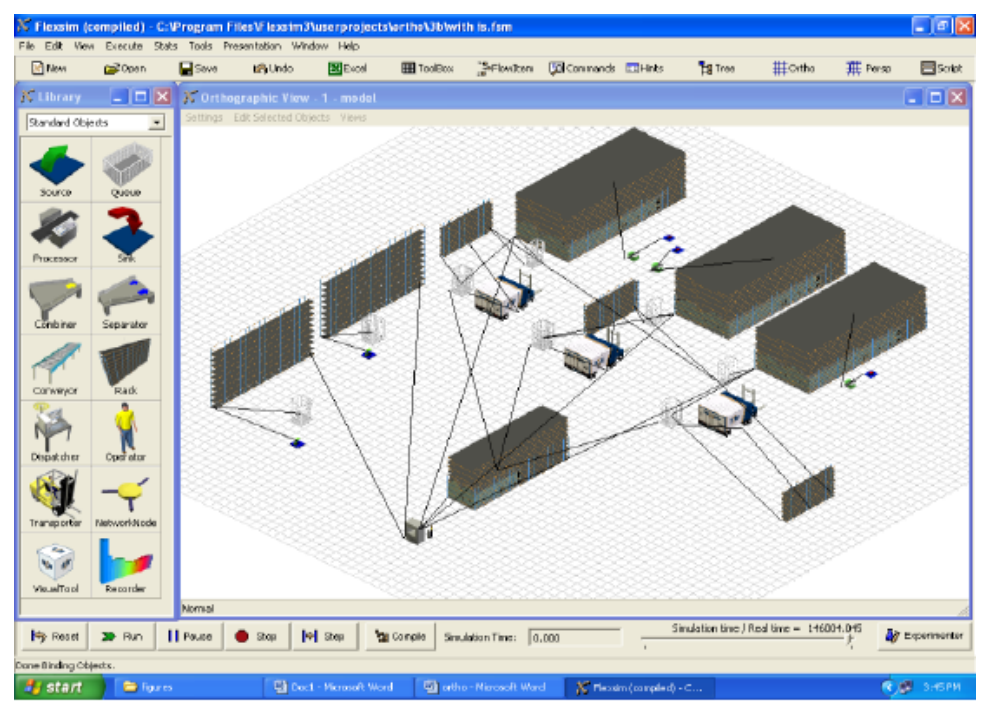

Figure 1 One vendor three buyer simulation model with IS

\subsection{Model assumptions and notations}

- Customer demand is normally distributed

- Production capacity $>0$ (i.e., infinite capacity)

- Demand in period ' $t$ ' for all buyer $\sum_{i=1}^{n} D i>0$

- $\quad \sum_{i=1}^{n} D i \leq$ production rate $\neq$ production capacity

- A single product flow through supply chain with 
- continuous review period

- If demand exceeds on hand inventory, it is considered as shortage

- Buyer \& Vendor have their own holding.

- Shortages were permitted but backorders not permitted

The following are the notations and inputs are used;

n total number of buyers, upto 5

$\mathrm{d}_{\mathrm{i}} \quad$ demand rate on buyer i $\mathrm{d}_{1}=10000, \mathrm{~d}_{2,3}=13000, \mathrm{~d}_{4,5}=17000$ units/year

$\mathrm{p} \quad$ vendor production rate (units/period), $30 \%$ more than $\sum d_{i}$

$\mathrm{h}_{\mathrm{v}} \quad$ vendor holding cost (\$4/unit/period)

$\mathrm{h}_{\mathrm{bi}} \quad$ buyer i holding cost (\$5/unit/period)

s Vendor's setup cost (200\$/setup)

$\pi \quad$ shortage cost (50\$/unit)

$\mathrm{a}_{\mathrm{t}} \quad$ transportation cost $(30$ \$/shipment)

\section{RESULTS}

The input values for this simulation are taken from Srinivas \& Rao (2006), Braglia \& Zavanella (2003), and Hans et al (2006). The results with sensitivity variables of simulation runs are depicted through Tables 1 to 3 and Figures 2 to 5. The simulation was run for three years with $20 \%$ simulation time as warmup time and with 5 replications. The Flexsim simulation software runs with maximum simulation time/ real time ratio as 160000:1.

The performance variable, fill rate has been calculated as,

$$
\text { fill rate }=\frac{\sum_{n=1}^{i}(D n-I n)}{\sum_{n=1}^{i} D n}
$$

The fill rate can be defined as the percentage of order that the entity is able to ship to its downstream customer which is the fraction of customer demands that are met from the stock (Ram Ganeshan, 1999). The various other performance variables such as along with sensitivity analysis is given in Tables $2 \& 3$.

The joint total economic cost (JTEC) in simulation model is more comparing to Genetic Algorithm model (Srinivas \& Rao, 2006a). The total cost in all the strategies increases with increasing number of buyers (Table 1, Fig.2 \& Fig.3). CS with delay and with information sharing gives fewer total costs when compare to CS with delay and basic model. It can be noticed that there is not much difference in two buyers' case. However, there is maximum of $16 \%$ cost difference in case of five buyers compare to GA model.

The cost saving occurs while shifting to CS with information sharing model from basic model (Fig. $4 \&$ Fig.5) it is more for five buyers. The sensitivity analysis factors such as, number of shipments, delay deliveries, shifting orders in information sharing and fill rate is given in Table 3. The number of shipments is less for three and more buyers. It is economical with information sharing due more fill rate and optimum utilization of shipments and the delay deliveries consistently less while buyers increasing. The ABQ decreases for model 1 to model 2 and model 2 to model 3 while AVQ increases. This phenomenon reduces JTEC because $h_{v}>$ $\mathrm{h}_{\mathrm{b}}$. The vendor trying to optimize the quantity for all the buyers by shifting the order among all the buyers through information sharing and also delaying the deliveries so that JTEC minimizes. Meanwhile the customer fill rate for all cases increases compare to basic CS and CS with delay delivery models. 
Table 1. JTEC comparison for both simulation and GA

\begin{tabular}{|c|c|c|c|c|c|c|c|c|c|c|c|c|}
\hline \multirow[b]{2}{*}{ model } & \multicolumn{3}{|c|}{1 vendor -2 buyers } & \multicolumn{3}{|c|}{1 vendor - 3 buyers } & \multicolumn{3}{|c|}{1 vendor -4 buyers } & \multicolumn{3}{|c|}{1 vendor -5 buyers } \\
\hline & GA & $\begin{array}{c}\text { simula- } \\
\text { tion }\end{array}$ & $\%$ diff. & GA & $\begin{array}{l}\text { simula- } \\
\text { tion }\end{array}$ & $\%$ diff. & GA & $\begin{array}{c}\text { simula- } \\
\text { tion }\end{array}$ & $\%$ diff. & GA & $\begin{array}{l}\text { simula- } \\
\text { tion }\end{array}$ & $\%$ diff. \\
\hline $\operatorname{cs}(\mathrm{M} 1)$ & 6032 & 6032 & 0 & 18414 & 20453 & +11 & 22117 & 23715 & +7.2 & 28992 & 33740 & +16.4 \\
\hline $\begin{array}{l}\text { cs, with delay } \\
\text { (M2) }\end{array}$ & 5880 & 5880 & 0 & 17382 & 19430 & +11.8 & 21691 & 23318 & +7.5 & 28230 & 31250 & +10.7 \\
\hline $\begin{array}{l}\text { cs, with delay \& } \\
\text { with information } \\
\text { sharing (M3) }\end{array}$ & 5768 & 5865 & +1.7 & 16979 & 18998 & +12 & 20958 & 23136 & +10.4 & 27070 & 30386 & +12.3 \\
\hline
\end{tabular}

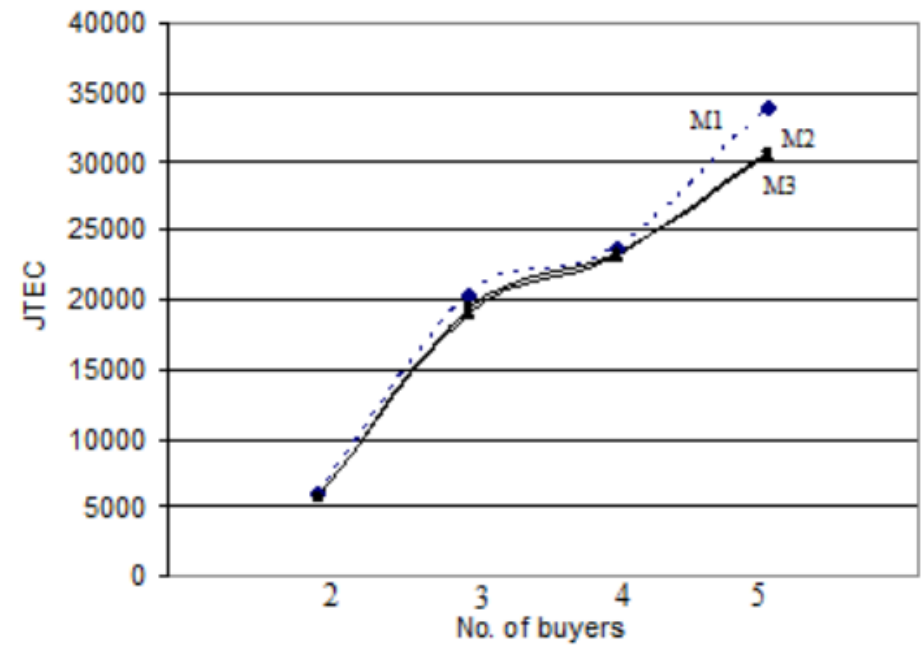

Figure 2 JTEC comparisons for 2,3,4,5 buyers for simulation

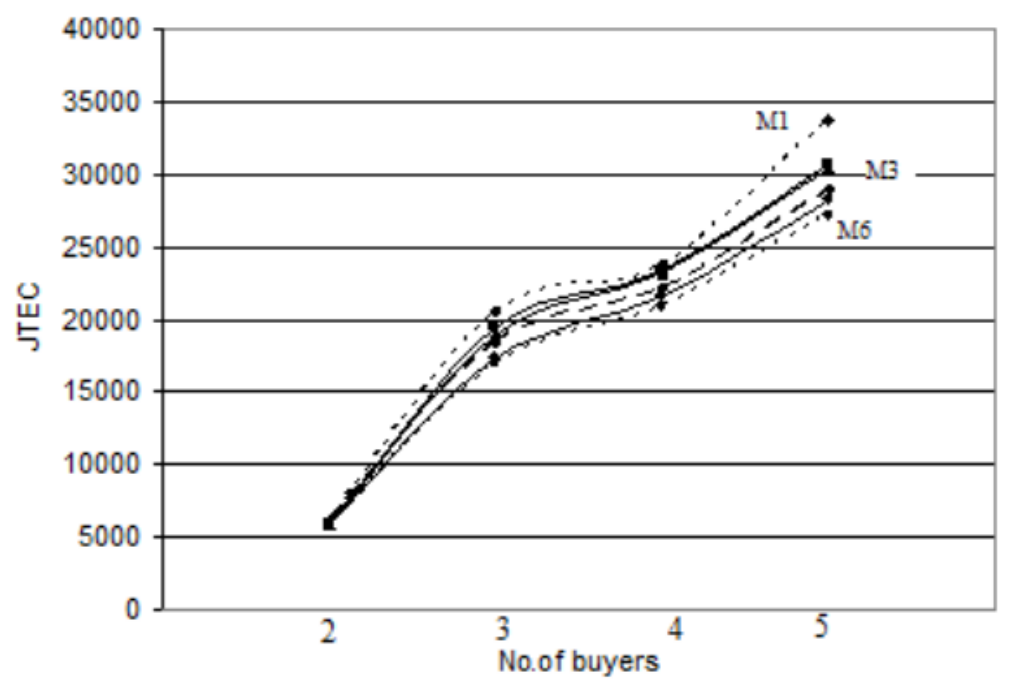

Figure 3 JTEC comparisons for 2,3,4,5 buyers for both simulation and GA 
Consignment Inventory Simulation Model for Single Vendor-Multi Buyers in a Supply Chain

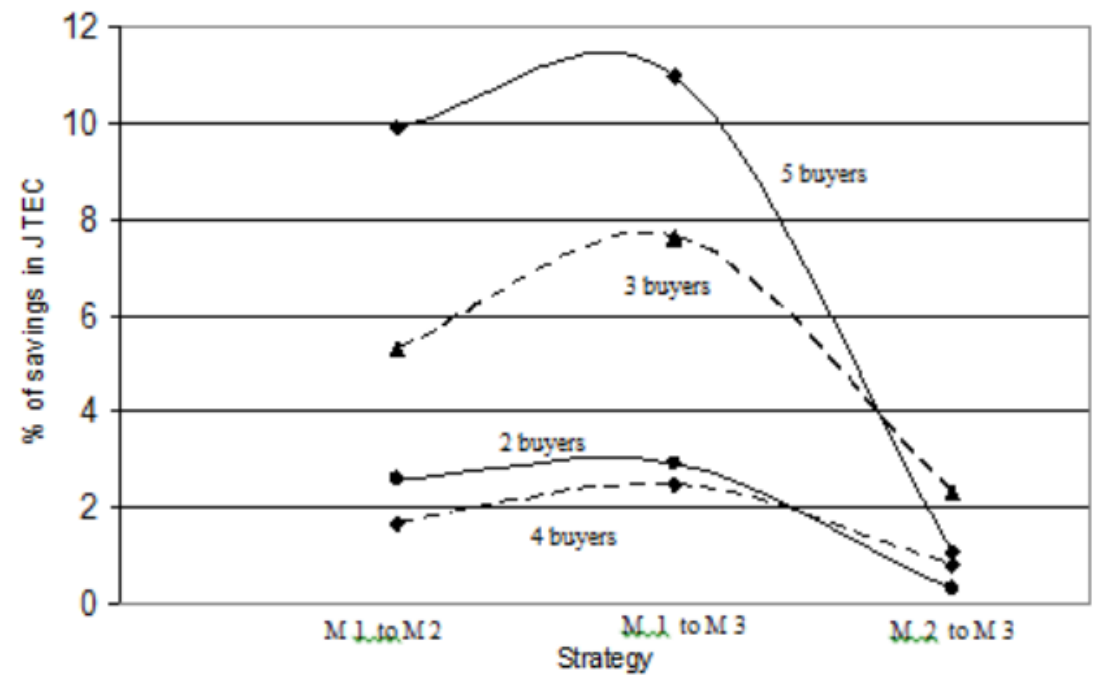

Figure $4 \%$ of savings in JTEC for different strategies in simulation

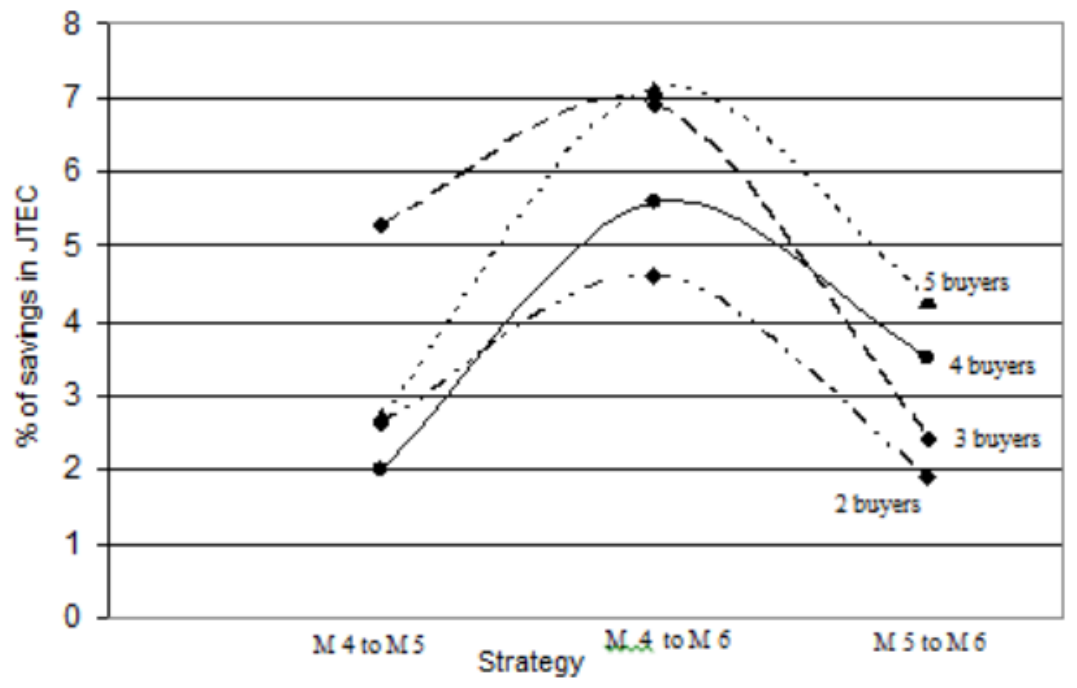

Figure $5 \%$ of saving in JTEC for different strategies in GA

Table 2 Average Buyer Quantity (ABQ) Vs Average Vendor Quantity (AVQ) in simulation model

\begin{tabular}{|c|c|c|c|c|c|c|c|c|c|c|c|c|c|c|c|c|}
\hline \multirow[t]{3}{*}{ Model } & \multicolumn{4}{|c|}{1 vendor -2 buyers } & \multicolumn{4}{|c|}{1 vendor - 3 buyers } & \multicolumn{4}{|c|}{1 vendor -4 buyers } & \multicolumn{4}{|c|}{1 vendor -5 buyers } \\
\hline & \multicolumn{2}{|c|}{ GA } & \multicolumn{2}{|c|}{ simulation } & \multicolumn{2}{|c|}{ GA } & \multicolumn{2}{|c|}{ simulation } & \multicolumn{2}{|c|}{ GA } & \multicolumn{2}{|c|}{ simulation } & \multicolumn{2}{|c|}{ GA } & \multicolumn{2}{|c|}{ simulation } \\
\hline & $\mathrm{ABQ}$ & AVQ & $\mathrm{ABQ}$ & AVQ & $\mathrm{ABQ}$ & AVQ & $\mathrm{ABQ}$ & AVQ & $\mathrm{ABQ}$ & AVQ & $\mathrm{ABQ}$ & AVQ & $\mathrm{ABQ}$ & AVQ & $\mathrm{ABQ}$ & AVQ \\
\hline M1 & 408 & 3. & 819 & 40 & 382 & 5 & 1520 & 502 & 45 & 126 & 15 & 24 & 376 & 127 & 250 & 02 \\
\hline M2 & 374 & 84 & 762 & 6 & 278 & 348 & 1360 & 45 & 305 & 380 & 1476 & 270 & 318 & 521 & 1896 & 533 \\
\hline M3 & 373 & 85 & 768 & 132 & 283 & 145 & 1468 & 452 & 295 & 371 & 1461 & 390 & 325 & 282 & 2349 & 730 \\
\hline
\end{tabular}

Table 3. Detail list of no. of shipments, delay deliveries and shifting quantities in information sharing

\begin{tabular}{|c|c|c|c|c|}
\hline & 2 buyers & 3 buyers & 4 buyers & 5 buyers \\
\hline Model & $\mathrm{M} 1 / \mathrm{M} 2 / \mathrm{M} 3$ & M1/M2/M3 & M1/M2/M3 & M1/M2/M3 \\
\hline $\begin{array}{l}\text { no. of } \\
\text { shipments }\end{array}$ & $7,7 / 8,8 / 5,8$ & $2,4,1 / 3,7,3 / 5,10,15$ & $3,4,4,4 / 4,4,4,5 / 4,4,6,4$ & $3,3,3,3,3 / 3,3,4,4,4 / 5,3,3,4,6$ \\
\hline \begin{tabular}{|l} 
delay \\
deliveries
\end{tabular} & $-,-/ 2,2 / 4,2$ & $-,-,-/ 1,4,1 / 4,9,8$ & $-,-,-,-/ 1,1,1,1 / 1,3,2,3$ & $-,-,-,-,-/ 1,1,1,1,1 / 1,2,2,3,2$ \\
\hline \begin{tabular}{|l|} 
shifting \\
orders $J_{i k}$
\end{tabular} & $\mathrm{j}_{12}=3, \mathrm{j}_{21}=0$ & $\begin{array}{c}\mathrm{j}_{12}=0, \mathrm{j}_{21}=0, \mathrm{j}_{31}=0, \mathrm{j}_{31}=4, \\
\mathrm{j}_{23}=9, \mathrm{j}_{32}=0\end{array}$ & $\mathrm{j}_{23}=2, \mathrm{j}_{43}=3$ & $\mathrm{j}_{21}=1, \mathrm{j}_{25}=1, \mathrm{j}_{3}=1, \mathrm{j}_{35}=1, \mathrm{j}_{41}=3$ \\
\hline fill rate $\%$ & $60 / 62 / 62$ & 95/96/97 & $97 / 97 / 98$ & $96 / 97 / 97$ \\
\hline
\end{tabular}




\section{CONCLUSIONS AND FUTURE WORK}

In this paper, we have developed a simulation model for consignment stock inventory control model in supply chain for single vendor multiple buyers dealing with a single product under stochastic conditions, for different operational strategies. The major implication of our approach is that the vendor is solely responsible for all inventory related decisions of the buyers. Which is established through information sharing, leading to less joint total economic cost compare to with delay and with out delay delivery models ie., basic CS model. Hence the approach of partial information sharing may be the convenient even though it requires some sort of system integrations at all the levels.

For a set of input values of Banerjee \& Banerjee (1994) gives appr. 50\% less cost compare to our single vendor three buyer CS with information simulation model. With reference to Srinivas \& Rao (2006), our single vendor two buyer simulation model with same input, the basic CS and CS with delay delivery models gives $\$ 9405$ and $\$ 8999$ compare to $\$ 6846$ and $\$ 6511$ of their single vendor single buyer. The cost difference in both the cases is less than 38 $\%$.

Future studies have to be made in the areas of consignment stock for multiple vendor multiple buyer dealing with multiple products under stochastic conditions. We have used normal distribution customer demand for our models, other distributions can be incorporated especially for perishable items.

\section{REFERENCES}

[1] Ballou, R.H. Business Logistics Management. Prentice-Hall, New Jersey, $3^{\text {rd }}$ ed., (1992)

[2] Banerjee, A \& Banerjee, S. A coordinated order-up-to inventory control policy for a single supplier and multiple buyers using electronic data interchange, International Journal of Production Economics, Vol.35, (1994). pp.85-91.

[3] Chidurala Srinivas, Strategies of Delay Delivery and Controllable Lead Time to Optimize the Total Cost in Supply Chain Consignment Inventory, International Journal of Production Technology and Management (IJPTM), 10(1), 2019, pp. 9-18.

[4] Braglia, M. \& Zavanella, L.E. Modeling an industrial for inventory management in supply chains: the consignment stock case, International Journal of Production Research, Vol.41, No.16, (2003). pp.3793-3808.

[5] Closs, D.; Roath, A.; Goldsby, T.; Eckert, J. \& Swartz, S. An empirical comparison of anticipatory \& response-based supply chain strategies, The International Journal of logistics management, Vol.9, No.2, (1998). pp.21-34.

[6] Vikrant Dongre and Malay Niraj, Supply Chain Management System with Maintenance Strategy for Reimbursement of Growth in Industry, International Journal of Mechanical Engineering and Technology, 9(4), 2018, pp. 571-576

[7] Corbett, C.J. Stochastic inventory systems in a supply chain with asymmetric information cycle stocks, safety stocks and consignment sock, Operations Research, Vol. 49. No.4, (2001). pp.487-500.

[8] Adenike Oluyemi Bello, Adekanmi Adeyinka Adegun, Sunday Chinedu Eze, Monisola Esther Alao, Babatunde Gbadamosi, Supply Chain Management: Risk Assessment in Automotive Industry Using Fuzzy-AHP Model, International Journal of Mechanical Engineering and Technology 9(12), 2018, pp. 552-562.

[9] Douglas, L.M. \& Cooper, M. Issues in supply chain management, Industrial Marketing Management, Vol.15, No.1. (2000). pp. 65-83.

[10] Drucker, P.F. Management's new paradigms, Forbes, October, (1998). pp.152-177.

[11] Hans, S.; Raafat, N.I.; \& Paul, B.L. Joint economic lot size in distribution system with multiple shipment policy, International Journal of Production Economics, Vol.102. (2006). pp. 302-316. 
[12] Za'faran Hassan and K.K Ramachandran. The Role and Importance of Information Sharing Between Collaborative Partners in Supply Chain Management. International Journal of Advanced Research in Management, 8(4), 2017, pp. 01-17.

[13] Hills, R. M. The single-vendor single-buyer integrated production - inventory model with a generalized policy, European Journal of Operational Research, Vol.97, (1997). pp.493-499.

[14] Hills, R. M. The optimal production and shipment policy for a single-vendor single buyer integrated production - inventory problem, International Journal of Production Research, Vol.37, (1999). pp.2463-2475.

[15] Houlihan, J.B. International supply chain management, International Journal of Physical Distribution and Materials Management, Vol.15, (1985). pp.22-38.

[16] Petrovic, D.; Roy, R. \& Petrovic, R. Modeling and simulation of a supply chain in an uncertain environment, European Journal of Operations Research, Vol. 109, (1998). pp.299-309.

[17] Ajay Verma and Dr. Anshul Gangele, Investigation Thought Decision-Making Trial and Evaluation Laboratory (Dematel) in Green Supply Chain Management Include Reducing and Recycling Pharmaceutical Waste for a Pharmaceutical Manufacturer in India, International Journal of Industrial Engineering Research and Development (IJIERD), Volume 3, Issue 2, JulyDecember (2012), pp. 58-73

[18] Ram Ganeshan. Managing Supply Chain inventories: A multiple retailer, one warehouse, multiple supplier, International Journal of Production Economics, Vol.59, (1999). pp.341-354.

[19] Simchi-Levi, D.; Kaminsky, P. \& Simchi-Levi, E. Design and Managing the Supply Chain Concepts, Strategies and Case Studies. McGraw-Hill International Division, Singapore. (2000).

[20] Simone Zanoni \& Robert W. Grubbstrom. A note on an industrial strategy for stock management in supply chains: modeling and performance evaluation, International Journal of Production Research, Vol.42, No.20, (2004). pp.4421-4426.

[21] Srinivas, Ch. \& Rao, C.S.P. Consignment stock policy with controllable lead time for effective inventory management in supply chains, International Journal of Manufacturing Technology and Management, (accepted for publication, \#02, 2006) (2006).

[22] Srinivas, Ch. \& Rao, C.S.P. Consignment stock policy for a single vendor and multi buyers using analytical and genetic algorithm inventory management in supply chains, unpublished work. (2006).

[23] Strader, T.J.; Lin, F. \& Shaw, M.J. Simulation of order fulfillment in divergent assembly supply chains, Journal of Artificial Societies and Social Simulation, Vol.1, No.2. (1998).

[24] Towill, D.R.; Naim, M.M. \& Winker, J. Industrial dynamics simulation models in the design of supply chains, International Journal of Physical Distribution and Logistics Management, Vol. 22, (1992). pp.3-13.

[25] Valentini, G. \& Zavanella, L.E. The consignment stock of inventories: industrial case and performance analysis, International Journal of Production Economics, Vol.81, (2003). pp.215224. 